\title{
Spontaneous (natural) splenoadrenorenal shunts in extrahepatic portal venous obstruction: a series of 20 cases
}

\author{
J B DILAWARI AND Y K CHAWLA
}

From the Department of Hepatology, Postgraduate Institute of Medical Education and Research, Chandigarh, India

SUMMARY Large spontaneous (natural) splenoadrenorenal shunt on splenoportovenography was seen in $20(9 \cdot 4 \%)$ of the 213 patients with extrahepatic portal venous obstruction. Significantly less number of patients had a bleed and oesophageal varices in this group compared with patients having no spontaneous shunt. There was, however, no significant difference in the age, splenic size, splenic pulp pressure, anaemia, thrombocytopenia and leucopenia between the two groups.

When portal circulation is obstructed, whether it be within or outside the liver, collateral circulation develops to carry the portal blood into the systemic veins. The hepatopedal circulating channels attempt to bridge the point of obstruction by shunting blood towards the liver while hepatofugal pathways form communications between portal and caval systems through oesophageal varices and occasionally through the retroperitoneal collaterals, the commonest being splenoadrenorenal shunt. We present data on 20 patients with extrahepatic portal venous obstruction in whom splenoadrenorenal shunts were observed.

\section{Methods}

PATIENTS

Between 1979 and 1985 extrahepatic portal venous obstruction (EHPO), defined as obstruction of the main portal vein and or splenic vein, was diagnosed on 213 patients by percutaneous splenoportovenography. Multiple films were taken at the rate of one film per sec during and after a rapid intrasplenic injection of $40 \mathrm{ml}$ Conray 420 . Presence of a large spontaneous portosystemic shunt was accepted, when the contrast drained along the collateral to

Address for correspondence: Dr J B Dilawari, Head of Department of Hepatology PGI. Chandigarh. India.

Received for publication 5 February 1987. clearly delineate the inferior vena cava. Splenic pulp pressure was measured percutaneously, routinely, before carrying out splenoportovenography by the method of Atkinson et al.' All the patients were subjected to a routine clinical, laboratory and upper gastrointestinal endoscopy examination. The size of each variceal column was assessed by a subjective grading from I to IV corresponding with that described by Paquet. ${ }^{2}$ Statistical analysis was done using the $\chi^{2}$ test with significance accepted at $5 \%$ level. Results were expressed as mean \pm SD.

\section{Results}

Twenty of 213 patients with EHPO showed splenoadrenorenal collaterals (so called spontaneous shunt) draining into the inferior vena cava (Figure). The mean age of these 20 patients with spontaneous shunts was $18 \cdot 7 \pm 9 \cdot 2$ years (range $5-52$ years). The ratio of men to women was $2 \cdot 3: 1$. Twelve $(60 \%)$ patients presented with both haematemesis and melaena, while 8 $(40 \%)$ presented with splenomegaly without upper gastrointestinal bleeding. Oesophageal varices were present in $15(75 \%)$ of the 20 patients. Of the eight patients who did not bleed five had no varices, while one each had grade II, III, and IV varices. On the other hand of the 12 patients with bleed only two had grade II varices while 10 had grade III and IV varices. The difference in the variceal sizes in the bleed and no bleed group was statistically significant $(\mathrm{p}<0 \cdot 05)$. 


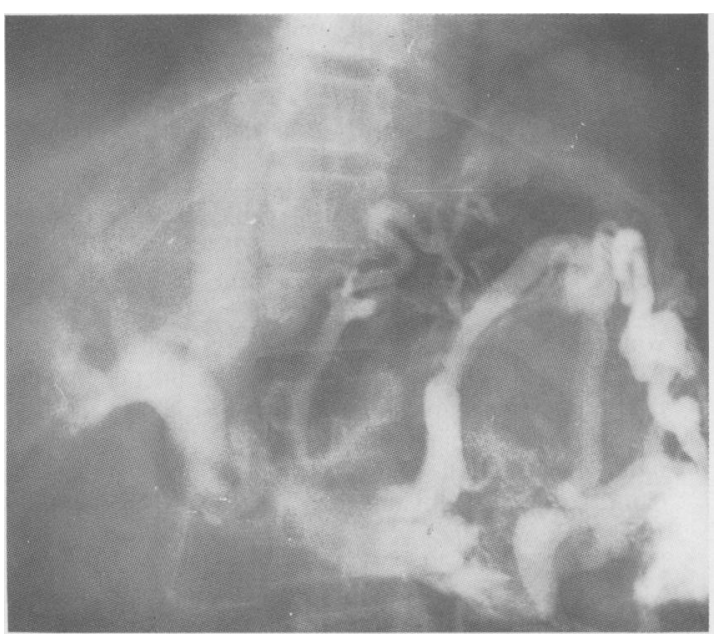

Figure Splenoportovenogram showing splenoadrenorenal shunt draining into the inferior vena cava.

The splenic size varied from $2-20 \mathrm{~cm}$ below the costal margin with a mean of $8 \cdot 0 \pm 4.7 \mathrm{~cm}$. The mean splenic pulp pressures were $27.5 \pm 7.9 \mathrm{mmHg}$ with a range from $17 \cdot 3 \mathrm{mmHg}$ to $36 \cdot 15 \mathrm{mmHg}$. There was no significant difference in the splenic pulp pressures in patients of spontaneous shunts with and without a bleed $(29.8 \mathrm{mmHg} v 30.49 \mathrm{mmHg})$. Severe anaemia $(\mathrm{Hb}<8 \mathrm{~g} \%)$, thrombocytopenia (platelets $<100000$ cu $\mathrm{mm}$ ), and leucopenia (TLC $<4000 \mathrm{cu} \mathrm{mm}$ ) were observed in $38 \%, 35 \%$, and $33 \%$ of patients respectively.

No clinically demonstrable ascites or abnormality of liver function tests (serum bilirubin, aminotransferases, alkaline phosphatase and proteins) was detected in these 20 patients. All the patients had normal coagulation parameters. No major complications were encountered after splenoportovenography except for pain at the injection site. The aetiology of portal vein thrombosis was not known in any of them. None of these patients had any history of umbilical transfusions in childhood.

There was no significant difference in the age, splenic size, splenic pulp pressures and prevelance of anaemia, thrombocytopenia, and leucopenia in patients with and without spontaneous shunts (Table).

One hundred and eighty one (94\%) of the 193 patients without spontaneous shunt had a bleed, compared with $60 \%$ of the patients in the spontaneous shunt group $(p<0 \cdot(001)$. Endoscopy showed oesophageal varices (grade III and IV) in $100 \%$ of the patients without spontaneous shunt compared with $75 \%$ of the patients with spontaneous shunt $(\mathrm{p}<0 \cdot 01)$.

\section{Discussion}

Literature on natural (spontaneous) splenoadrenorenal collaterals is extremely scanty. These were first thought to be a consequence of long standing portal hypertension. Edwards, however, at necropsy demonstrated their presence even in cases without portal hypertension.

Natural (spontaneous) shunts may occasionally become so prominent as to resemble surgically made shunts. Conflicting data are available on the effect of spontaneous (natural) shunts on gastrointestinal bleeding.

The belief that spontaneous shunts are effective in preventing the development of varices and gastrointestinal bleeding may be partially true. Although in our study significantly more patients $(40 \%)$ with spontaneous shunt did not bleed compared with only $6 \%$ of patients without spontaneous shunt, yet a sizable number $(60 \%)$ bled despite the development of spontaneous shunt. The study by Alvarez $\mathrm{et} \mathrm{al}^{4}$ on 108 patients with extrahepatic portal venous obstruction also showed that the mere presence of a natural shunt did not totally prevent variceal bleeding. In their series $19(17.5 \%)$ of the 108 patients had natural splenoadrenorenal shunts of various sizes and of these $12(64 \%)$ presented with a bleed. The remaining seven $(36 \%)$ patients had no bleed. Another interesting fact in their study was a decrease in the variceal size on repeat endoscopy after $2 \frac{1}{2}$ years in two patients and no change in one. This may indicate that in some of the patients, varices decrease or may even disappear over the years, presumably by an increased blood flow through the shunt.

Most of the other studies on spontaneous shunts are in patients with cirrhosis. Nunez et al in a follow

Table Comparative data in patients with portal venous obstruction, with and without spontaneous shunts

\begin{tabular}{|c|c|c|c|}
\hline & $\begin{array}{l}\text { With } \\
\text { spontaneous } \\
\text { shunt }\end{array}$ & $\begin{array}{l}\text { Without } \\
\text { spontaneous } \\
\text { shunt }\end{array}$ & Pvalue \\
\hline Patients (n) & $2(0(9 \cdot 4 \%)$ & $193(90 \cdot 6 \%)$ & - \\
\hline Sex M:F & $2 \cdot 3: 1$ & $3 \cdot 7: 1$ & NS \\
\hline Age (yrs) Mean \pm SD & $18 \cdot 7 \pm 9 \cdot 2$ & $17 \cdot 8 \pm 11 \cdot 3$ & NS \\
\hline Bleed & $12(60 \%)$ & $181(94 \%)$ & $<0.001$ \\
\hline Noblecd & $8(40 \%)$ & $12(6 \%)$ & $<0 \cdot 001$ \\
\hline \multicolumn{4}{|l|}{ Ocsophageal varices } \\
\hline Present & $15(75 \%)$ & $193(100 \%)$ & $<0 .(1)$ \\
\hline Absent & $5(25 \%)$ & $0(0 \%)$ & $<0 \cdot 01$ \\
\hline Spleen size $(\mathrm{cm})$ Mean $\pm \mathrm{SD}$ & $8 \cdot() \pm 4 \cdot 7$ & $7 \cdot() \pm 4 \cdot 4$ & NS \\
\hline \multicolumn{4}{|l|}{ Splenic pulp pressure } \\
\hline Mean $\pm \mathrm{SD}(\mathrm{mmHg})$ & $27 \cdot 5 \pm 7 \cdot 9$ & $32 \cdot 7 \pm 8 \cdot 2$ & NS \\
\hline Anacmia & $38 \%$ & $64 \%$ & NS \\
\hline Thrombocytopenia & $35 \%$ & $17 \%$ & NS \\
\hline Leucopenia & $33 \%$ & $30 \%$ & NS \\
\hline
\end{tabular}


up of two years did not observe recurrent gastrointestinal bleeding in patients with large spontaneous splenorenal shunts. ${ }^{5}$ Summerskill $e t$ al $^{6}$ and Wexler $e t$ $a l^{\prime}$ have stated that in patients with collateral circulation especially in the presence of large spontaneous shunts the portal pressures are reduced to normal and bleeding is prevented. Rousellot ${ }^{X}$ and Hamilton," however, have found that neither the incidence nor the severity of bleeding decreased in the presence of spontaneous shunts. In fact Hamilton" noted that the majority of his patients with large spontaneous shunts had higher portal pressures.

Although the patients with spontaneous shunts had a lower mean splenic pulp pressure, compared with those without spontaneous shunts, it did not reach statistical significance, possibly because of a small number of patients in the spontaneous shunt group. Among the patients with spontaneous shunt, however, the splenic pulp pressure was very similar in the group with or without bleed. Thus we found a poor correlation between variceal bleed and portal pressures as also observed by other workers. "' There was, however, a significant correlation between the variceal size and bleed among the patients with spontaneous shunt group - that is, significantly more patients with bleed had grade III and IV varices compared with those without a bleed.

Lam et al" have not shown a decrease in the incidence of bleeding but interestingly have shown an increased incidence of spontaneous encephalopathy with large bore spontaneous shunts. The reason being, all their patients had cirrhosis of the liver.

We did not encounter encephalopathy in any of our patients, because all had EHPO and no cirrhosis.

In conclusion large spontaneous (natural) splenoadrenorenal shunt may protect some of the patients with EHPO from variceal bleed.
We would like to thank Ashok Kumari for her secretarial help.

\section{References}

1 Atkinson $\mathrm{M}$, Sherlock $\mathrm{S}$. Intrasplenic pressure as index of portal venous pressure. Lancet 1954; i: 1325-7.

2 Paquet KJ. Prophylactic endoscopic sclerosing treatment of the oesophageal wall in varices. A prospective controlled randomised trial. Endoscopy 1982; 14: 4-5.

3 Edwards EA. Functional anatomy of portal systemic communications. Arch Intern Med 1951; 88: 137-54.

4 Alvarez F, Bernard O, Brunette F, Hadchouel P, Odievre M, Alagille D. Portal obstruction in children. 1 . Clinical investigation and hemorrhage risk. J Paediatrics 1983; 103: 696-702.

5 Nunez DJr, Russel I, Yrizarry J, Pereiras R, Viamonte MJr. Portosystemic communications studied by transhepatic portography. Radiology 1978; 127: 75-9.

6 Summerskill WHJ, Davidson EA, Sherlock S, Sterner RI. The neuropsychiatric syndrome associated with hepatic cirrhosis and an extensive portal collateral circulation. Q J Med 1956; 25: 245-66.

7 Wexler MJ, Maclean LD. Massive spontaneous portal systemic shunting without varices. Arch Surg 1975; 110: 995-1002.

8 Rousellot LM, Moreno AH, Panke WF. Studies in portal hypertension IV. The clinical and physiopathologic significance of self-established (non-surgical) portal systemic venous shunts. Ann Surg 1959; 150: 384-410.

9 Hamilton LC, Sullivan BH. Natural portosystemic venous shunts in portal hypertension. Med Ann DC 1961; 30: 654-9.

10 Reynolds TB, Redeker AG, Geller HM. Wedged hepatic venous pressure. Am J Med 1957; 22: 341-50.

11 Lam KC, Juttner HU, Reynolds TB. Spontaneous portosystemic shunt. Relationship to spontaneous encephalopathy and gastrointestinal hemorrhage. Dig Dis Sci 1981; 26: 346-52. 